\title{
American Behavioral Scientist
}

\author{
Special Issue on
}

\section{Philanthropic Foundations:}

\section{Comparative Perspectives on the United States and Germany}

\author{
Here: \\ Foundations in Switzerland \\ by \\ Georg von Schnurbein ${ }^{1}$ \\ and \\ Marybel Perez ${ }^{2}$
}

\begin{abstract}
This article considers the current state of the Swiss foundation sector in relation to both its own historical development and its counterparts in Germany and the US. Through a descriptive analysis of the database of the Center for Philanthropy Studies (CEPS) of 11619 foundations and a case study of 2679 foundations in seven cantons we show that despite the similarities to Germany in historical growth and to the US in asset distribution Swiss foundations are unique in density and fields of activity they pursue. In terms of roles Swiss foundations are close to US foundations in their emphasis on complementarity, but in terms of approach are close to Germany with a
\end{abstract}

\footnotetext{
${ }^{1}$ Georg von Schnurbein is associate professor at the Faculty of Business and Economics at the University of Basel (WWZ) and founding director of the Center for Philanthropy Studies (CEPS) at the University of Basel, Switzerland. Before, he was a researcher and PhD-student at the Verbandsmanagement Institut (VMI) of the University of Fribourg/ $\mathrm{CH}$. He is the author of various publications on subjects such as foundation management, nonprofit governance, and nonprofit finance.

${ }^{2}$ Marybel Perez is senior researcher at the Center for Philanthropy Studies at the University of Basel, Switzerland. Her previous appointments include adjunct lecturer at Parsons: The New School for Social Research in Paris and at ESSCA School of Management in France. She was research fellow for Eurosphere, a 6th Framework Programme of the European Commission at the University of Bergen, Norway, where she obtained her PhD.
} 
significant number of grant-making foundations. Overall, it is found that despite some socioeconomic transformations in Switzerland the categorization of the foundation sector close to a liberal model has not fundamentally changed.

\section{Keywords}

Philanthropy, foundations, Switzerland, welfare state regimes

\section{Introduction}

The Swiss foundation sector is significant in size and societal perception. This is a result of political and legal stability, economic growth and the geographic situation (Purtschert et al. 2007). In contrast to most European countries, Switzerland was not actively involved in the two World Wars and the political system constantly developed since 1848 from a representative democracy to a direct democracy with high levels of individual legal autonomy. Additionally, Switzerland developed from an agricultural economy to a highly specialized and technology-driven economy, attracting highly qualified workers from all over the world. Throughout the $20^{\text {th }}$ century and based on the political neutrality, Switzerland became a significant international financial market place, which also led to the creation of foundations once the money was in the country. While foundation law in the US has been repeatedly changed toward tighter regulation since 1913 (e.g. Leat 2016) the Swiss foundation law, established in 1912, remained unchanged for nearly 100 years. Only in 2006, a revision introduced new standards of accountability and a right for founders to change the foundation purpose under restricted conditions. Especially in the past years, the geographic situation in the center of Western Europe, good travel conditions to all parts of the world, and the location of many international organizations facilitated the settlement of globally active foundations such as the Global Fund to fight Aids, Tuberculosis and Malaria, the Global Alliance for Vaccines and Immunization (GAVI Alliance) or the Global Alliance for Improved Nutrition (GAIN) - all registered as foundations under Swiss law. 
On the contrary, the fragmentation, the level of professionalization, and the lack of transparency are often criticized (Müller-Jentsch 2014). Basically, a foundation is a legal form with low regulation. Thus not all foundations are charitable. Although all foundations have to be registered officially, no further reporting obligations exist. In contrast with the long US tradition of making public financial forms and annual reports (Hammack and Anheier 2013), Swiss foundations only have to report to the state supervisory authority which does not make the information public. Thus, information on financial size of the sector and of individual foundations are hard to find or nonexistent. Therefore, the study of the sector tends to focus on a number of organizational aspects found in a few large databases and on case studies and small$\mathrm{N}$ studies when further data is available -see below. As will be further shown most of the Swiss foundations are small and limited in their activities. In consequence, the level of organization and professionalization of the sector is weak -a weakness that frequently affects foundations at large (Hammack and Anheier 2013).

In recent years, the foundation sector has become more visible and at the same time, interest of the public and politics for the sector has increased. This development opens up for a debate on the foothold of foundations in society.

Building on the augmented number of studies on the Swiss foundation sector in recent years, this study examines a unique data set to analyze the potential of the Swiss foundation sector to induce social change and social impact. Given legal differences in defining foundations, we restrict our study on charitable foundations under Swiss law. Not included are other foundations such as pension funds or private purpose foundations (Arrivillaga and von Schnurbein 2014). We use two data sources. First, we refer to a database of the Center for Philanthropy Studies (CEPS) including 11619 Swiss charitable foundations collected by the end of 2014 including information on the purpose, geographical reach, age, and individuals on the board of foundations. The database is regularly updated and the classification of the fields is done according to the International Classification of Non-profit Organizations (Salamon et al. 2004). The basis of the database is the Swiss register of commerce, 
where all foundations are included. Data is extracted using data algorithms and all foundations were categorized by researchers following a coding book. The second data source is based on information provided by cantonal supervisory authorities of seven cantons. The cantonal supervisory authorities are responsible for charitable foundations with a regional or cantonal purpose. Foundations with a national or international purpose are under federal supervision (von Schnurbein 2013). This dataset consists of 2679 foundations from the Cantons Appenzell Ausserrhoden, Geneva, Neuchâtel, St. Gallen, Tessin, Thurgau, and Vaud. The database includes information on asset size per foundation, fields of activities and age for a period of four years between 2010 and 2014. As this database is anonymized, it cannot be linked to the first database. Thus, in the further analysis, we will use the first database to address the descriptive issues in terms of fields of activity and mode of action. The second database will be used for a causal analysis of the development of the sector in recent years.

This article is structured as follows. First, a brief historical development of foundations in Switzerland and the latest figures on Swiss foundations is presented in a comparative manner. We show that foundations in Switzerland are not comparable either in absolute numbers or in density with the Germany and the US, where density in Switzerland is seven times higher than in those countries. We also show that the distribution of assets in Switzerland follows a similar pattern to the US and we consider the implications for the development of the sector with an analysis of seven Swiss cantons. Second, we position Swiss foundations in the framework of regime typologies. We support findings from existing studies on the categorization of the country's foundation sector vis-à-vis the different typologies. This position usually locates between the Germany and the US in each of the regime typologies. The third section we consider how Swiss foundations balance their approach, roles and purposes. With a particular focus on foundations' approach and purposes, we find that similar to Germany, grant-making foundations count for slightly more than half of the Swiss foundations and we show that this type of foundations is primarily focused on the purposes of relief and protection. Moreover, in line with grant- 
making foundations purposes they primarily work on the fields of social services and education and research. The last section ends with a discussion of the relationship of the Swiss foundation sector to both, the state and the market. We hypothesize that Swiss foundations have to overcome their traditional distinctiveness from the state in order to participate more effectively in the solution of societal problems and to enhance their legitimacy. The relation to the business sector is very well developed and Swiss foundations are more open to adopt concepts such as impact investing than foundations in Germany seem to be. Finally, Switzerland plays an important role as global hub of philanthropy. Given the stable political situation, the high competencies of the financial market, and the humanitarian tradition of the country, international funding organizations such as The Global Fund are located in Switzerland and organize their global activities through this country.

\section{The foundation sector in Switzerland}

In contrast with the US but comparable to Germany, in Switzerland a foundation is a legal entity that can be used for charitable and non-charitable purposes. While charitable foundations profit from tax reliefs, non-charitable foundations have no tax advantages compared to other legal entities. A charitable foundation does not necessarily rely on a large fortune. In comparison to US tax legal regulations, a Swiss foundation may be categorized either as 501 (c)(2) or 501 (c)(3) organization (see Hammack and Smith in this issue). For instance, Greenpeace Switzerland is constituted legally as foundation. However, the major share of Swiss foundations is founded with an endowment.

The oldest foundations still existing in Switzerland date back to the $13^{\text {th }}$ and $14^{\text {th }}$ century. Foundations such as "Inselspital" or "l'hôpital de bourgeoisie fribourgoise" were set up to fund hospitals. However, the modern foundation sector is a result of the last one hundred years. At the time of the codification of the foundation law in 1912, a total of 211 charitable foundations existed. As shown in figure 1 the development increased in the 1960s. However, $60 \%$ of the foundations have been 
established since the1990s. Thus, the Swiss foundation sector shows a similar development as in Germany where $71 \%$ of the foundations where established in the same period (see respective articles in this volume). Since 2010, the growth has slowed down, but still about 350 foundations are established every year. At the end of 2016, a total of 13172 charitable foundations existed. Put into relation to the country's size there are 15.8 foundations per 10.000 inhabitants, which is a far higher value compared to Germany (2.3) and the US (2.6) (see respective articles in this volume). We see as reasons for this high concentration a fruitful combination of legal continuity in the past century, a - in the European context - liberal welfare state promoting private engagement in culture and social services, and a high concentration of private wealth.

[Figure 1 about here]

Although one can find foundations in all Swiss regions, most foundations are concentrated in the major cities. Zürich has the highest number of foundations and Basel is the canton with the highest foundation density (see table 1).

[Table 1 about here]

While most foundations are located in major cities, most foundations focus their activities at local and cantonal level. Table 2 shows that among 10719 foundations reporting a geographical focus, $30.8 \%$ operate on the local level and $18.5 \%$ on the cantonal level. In this regard, Hammack and Anheier (2013) explain that local focus and particularism are strong forces in the foundation sector, which are also present in the US. Nevertheless, interest in helping beyond national borders is another visible trend in the foundation sector (Hammack and Anheier, 2013). As stated before, Switzerland plays an important role in global philanthropy hosting both private wealth and international organizations. As a consequence, slightly more than one in five foundations have an international focus. 
[Table 2 about here]

Table 3 shows the distribution of foundations in the five main fields of activity in Switzerland: culture and recreation, education and research, health, social and environment. Foundations primarily focus on culture and recreation (3778 foundations), social services (3553 foundations) and education and research (3317). In contrast with Germany, where foundations tend to work on multiple fields and only a small number specialize in one field, Swiss foundations significantly specialize in one field. This is particularly the case of culture and health where more than twothirds of foundations focus exclusively on these fields. Further analysis of the fields in relation to foundations' approaches is presented in section 3.

[Table 3 about here]

Similarly to the United States and Germany, the size of endowments is significantly concentrated in a small number of foundations. In total, Swiss foundations have an estimated fortune of $\$ 70$ billion (CHF 70 billion) and annual pay-outs of $\$ 2$ billion (CHF 2 billion) (von Schnurbein 2013). More detailed financial information of a study of 1'727 foundations reveals that most foundations are very small (Eckhardt et al 2017). In the study, $31 \%$ of the foundations held $0.4 \%$ of the total capital and the $8 \%$ of largest foundations held $34 \%$ of the total capital. These estimations are likely to apply at a larger scale. For instance, according to Hammack and Anheier (2013) in the US the 100 largest foundations held one-third of the total assets in 2009.

Further analysis of foundation's financial performance helps to consider the implications of the distribution of assets and their consequences on the performance of the sector. In the dataset of the foundations from seven cantons, the $50 \%$ larger foundations hold $98 \%$ of the capital. The overall capital sums up to 14.9 billion USD. However, we can say more about the development in the sector by looking at the range of four years. Although the economic crisis did hit Switzerland as other countries, the resulting consequences on the financial markets had an impact on the 
foundations. In table 6, we use the median to divide the foundations according to size (median $717353 \mathrm{CHF}$ ) and four-year-growth (0.011). As one can see, $29.7 \%$ of the smallest foundations report a growth in assets below the median ("cold"), whereas $29.8 \%$ of the largest foundations report a positive development ("hot"). Hence, small foundations seem to have more difficulties in managing the changes on the financial markets. The divide between small and large foundations becomes even more obvious when looking at the capital. As stated before, the $50 \%$ largest foundations hold $98 \%$ of the capital. Among those, the most successful foundations are also wealthier with $67.5 \%$ of the capital. In contrast, the $29.7 \%$ small and cold foundations share $1.1 \%$ of the capital. Thus, we see an increasing divide between small and large foundations in regard of the financial means. While the small ones loose capital and become even smaller, the largest ones are able to further increase their capital. One result of this trend is an increase of liquidations. Since 2009, more than 1200 foundations were liquidated due to mergers, capital consumption, or irrelevance of the purpose (Eckhardt et al. 2017). Additionally, we can see that the largest foundations are more likely to cover several fields of activities. It is clear that foundations with more assets are more likely to cover more fields of activities, but at the same time the broader spectrum offers them more space for strategic choices.

[Table 4 about here]

\section{Swiss foundations in the perception of different typologies}

The analysis of welfare regimes is helpful to understand the societal role of nonprofits in general and the foundation sector more specifically. While the position of Germany in some of the regime typologies has changed, the positions of the foundation sector in Switzerland have not fundamentally changed. However, the separation into grant-making, operative, and mixed foundations together with the skewed allocation of assets hinders the description of a clear picture of the foundation sector. Among the grant-making foundations, the few large 
foundations give distinction to the public perception of the sector as a whole. In recent years, these foundations have built their own field within the civil society (Eckhardt et al. 2017). They established their own association, established a research center on philanthropy and increased transparency and communication about their activities. Their orientation beyond the civil society sector is more directed towards business than the state. First, many of these foundations have strong personal overlaps with the business sector through board members or experts. Second, the traditional weak relations between public authorities and philanthropic foundations can be seen as an expression of the principle of private autonomy (Arrivilaga and von Schnurbein 2014). Among the operative foundations, changes in public financing have forced these foundations to become more market-driven. For example, in the social service sector, public funding was transferred from the federal to the cantonal level with the intend to better deal with different regional cost structures and service demands. Along with this change, the kind of financing changed from subsidies to contracts. Hence, foundations running social institutions have shifted from quasipublic agencies to nonprofit corporations with a higher degree of responsibility for private funding. Following the typology on size and approach developed by Anheier et al. (see article in this volume), we find support for all four types. Only a few more grantmaking foundations than the members of Swiss Foundations can be called professional philanthropists. Due to capital constraints most of the grantmaking foundations may be counted as engagement foundations. Among the operative and mixed foundations, service providers can be found especially in the fields of arts and culture, social and health services, and education. The legal form of the foundation is a commonly used structure for the preservation and management of real estate necessary to fulfill the purpose, e.g. museums, schools, elderly homes, etc.

In respect to the welfare regimes we apply Anheier and Daly's classification (2007) following previous studies on the Swiss foundation sector (Purtschert et al. 2007). Most likely, Switzerland is situated between the liberal and the social democratic model (Helmig et al. 2010). Indicators for the liberal model are the high reliance on 
private action, the mix of funding sources, and the size of volunteer activities. Closer to the social democratic model is the size of workforce in the social services, a high public funding of social nonprofits, and the increasing social security in the past twenty years (Helmig et al. 2010). In a study of the foundation sector, Purtschert et al. (2007) defined four clusters corresponding to different regimes. The liberal cluster entails large grant making foundations which define their funding politics independently from the state. The corporatist cluster consists of operative foundations that fulfill public tasks and are mainly funded by the state. In the social democratic cluster large foundations for social services work closely together with state agency and fund joint projects. Finally, the business-related cluster entails the growing number of corporate foundations that are situated between the companies and the civil society as well as a smaller number of shareholder foundations which own a company and use their dividends to support public purposes. Depending on the cluster, proximities to state and business vary. In the corporatist and social democratic cluster, the relationship between the state and the foundations is close and often based on the subsidiary principle, e.g. the foundations (and other nonprofits) execute task that the state has to perform. As a consequence, financial dependency on the state is high. In the liberal and business model, the foundations are closer connected to the market. Additionally, the foundations in the liberal cluster often serve as convener or intermediary between other actors (von Schnurbein 2013).

Regarding the remaining regime typologies, the Swiss foundation sector is again difficult to neatly fit into one category. According to the Varieties of Capitalism typology (Hall and Soskice, 2001) Switzerland is a coordinated market economy (CME). As described above, while an important part of the foundations work with governments or depend on their funding, the share of foundations independent from governments is equally important. As a result, the Swiss foundation sector will most likely fit into what Anheier describes as CME-like (see the introduction to this volume). These trends will also place the Swiss foundation sector in between the liberal-corporatist axis on the Social Origins theory of Salamon and Anheier (1999). Finally, in the Welfare Regimes typology (Esping-Andersen 1990) Switzerland is 
classified as a conservative country. However, general trends of decreasing decommodification and small increase in stratification (Bambra 2006, Gerber and Gerner 2017, Scruggs and Allan 2008) move Switzerland close to the liberal border which would not affect the overall somewhat liberal categorization of the foundation sector.

\section{The balance of approach, roles and purposes of Swiss foundations}

Our analysis concentrates on the approach and purposes of Swiss foundations and drawing on early literature we briefly consider foundation's roles. For the analysis of the approach and purposes we used the database of 11619 Swiss charitable foundations. The analysis follows the framework proposed by Anheier in the introduction to this volume. Therefore, the foundations were classified according to approach and purpose as defined by Anheier. The fields studied are the result of the application of the International Classification of Non-profit Organizations to our database (Salamon et al. 2004).

Looking at the purposes first, figure 1 shows that foundations in Switzerland are significantly concentrated on activities related to relief (40\%) and protection (36\%), although foundations devoted to change do not constitute a negligible part of the sector $(24 \%)$. Although these results suggest that foundations in Switzerland are considerably more interested than German foundations in pursuing the less traditional philanthropic purpose of change, the results, however, cannot be compared. For our analysis we created mutually-exclusive categories while the German study is based on multiple answers.

In the CEPS database, 10495 foundations fit to one of the three approaches studied (for the remaining part, the existing information was not useful). We find a high comparison of the Swiss foundation sector and the German counterpart. As figure two shows, in both countries, grant-making foundations constitute more than half of the sector. The differences show in the proportions of operating and mixed 
foundations where operating foundations in Switzerland constitute one-third of the sector while in Germany they equally share with mixed foundations the remaining half of the German foundation sector.

The examination of the relation between purpose and approach shows that priority of purposes change according to the approach of the foundations (Table 5). It becomes obvious, that due to the comparably similar legal regulations, Swiss and German foundation sector show a similar pattern of approaches. A significant number of operating and mixed foundations focus on protection first and relief second, while grant-making foundations significantly focus on relief in first place and change in second place. As a result, while operating and mixed foundations engage in traditional philanthropic purposes, grant-making foundations are additionally considerably interested in purposes seeking to generate structural transformations as defined in the introduction of this volume. Taking into account that grant-making foundations are the largest part of Swiss foundations, the overall significance for the sector of both purposes relief and change may be important.

[Table 5 about here]

The study of the distribution of approach with regards to fields shows that grantmaking foundations are significantly focused on social services and education and research (table 6). This pattern is linked to the focus of grant-making foundations on the purposes of relief and change described above. It is also shown that operating foundations primarily focus on culture and recreation while mixed foundations focus on culture and recreation and education and research, both fields considered of traditional philanthropic purpose -i.e. protection. Regarding the fields of less attention it is observed that health issues are almost equally tackled by both operating and grant-making foundations while environmental issues are significantly tackled by grant-making foundations.

[Table 6 about here] 
Finally, due to the fact that our dataset do not allow for further analysis on the roles of foundations, we focus our analysis of roles on early research and recent trend developments.

In contrast with German foundations where build-out and substitution are more important than complementarity $(71 \%, 63 \%$ and 34\%, respectively), for Swiss foundations complementarity and innovation are the two main roles pursued. This emphasis on complementarity places Swiss foundations close to their US counterpart (Hammack and Anheier, 2013). A decade after Purtschert et al. (2007) argued that complementary is the most important role of Swiss foundations the view is not likely to have changed. The trends guiding Purtschert et al.'s analysis still hold. Public sector spending on education, culture and social and health care has steadily increased in last decades constituting about $65 \%$ of the total public spending in 2013, while approximately $60 \%$ of the foundations focus in these same fields. Regarding innovation, it was established by Purtschert et al. that Swiss foundations moderately identify themselves with this role and there is no sign that this view has significantly changed during the decade.

[Figure 2 about here]

\section{Discussion and conclusions}

As the country itself, the Swiss foundations cannot be put all in one box. As previous studies have shown, different clusters occur when analyzing the relation to the state and the different purposes of the foundations. Following the social origins theory, Switzerland is positioned between the US and Germany. The Swiss foundations sector shows similarities with the US in terms of liberal foundations that position themselves independently from the state and might even act in opposition to the state (Dowie 2002; Hammack and Anheier 2013; Toepler 2007). The business related cluster follows the global ideas of corporate philanthropy, embracing new concepts 
such as impact investing and shared value (Porter and Kramer 2011). On the other hand, the more corporatist cluster and the social democratic cluster of the foundation sector can be compared to foundations in Germany in close relation to the state and in high dependence on state funding. However, even in these clusters, a distance to state policies can be recognized. In the realm of complex societal problems such as the climate change or migration, where joint efforts are necessary, this attitude hinders foundations to connect with state authorities. Especially, foundations may add to problem-solving through the role as convener and intermediary between nonprofits, market, and the state (von Schnurbein 2010). Additionally, exchange between state actors and foundations rarely happens. In recent years, the foundations have started to redefine their relation to the state. Instead of highlighting their own independence and apolitical self-concept, they are looking for a better connection to and in the state. As stated in the introduction, the foundation sector today is increasingly in the spotlight of public interest. Sources of legitimation are less to be found in the donation for a charitable purpose itself, but more in the outcomes of the activities. This development is independent of the chosen purpose or approach. Even foundations with the purpose of protection or relief have to proof that they make a difference. Hence, foundations need to be well embedded in their social environment and need to provide evidence-based documentation of their activities.

As in both countries, the US and Germany, the Swiss foundation sector is very heterogeneous, but concentrated in assets. In a sample of 2769 foundations, $50 \%$ of the foundations hold $98 \%$ of the capital. And the larger foundations manage to even grow while the smaller foundations decline. This development leads to high interests in new strategies such as pooling of assets or spend-down on the one hand. On the other hand, the business relation of the larger foundations increases. Pooling or spend-down strategies are for many small foundations the only options to keep up their mission. Large foundations become more open to business models and strategies, especially, in terms of communication and investments. Generally, in terms of capital investment, Switzerland is closer to the US than to Germany, e.g. 
investments are more active. Recent developments emphasize the understanding of a foundation as "impact unit", combining the social impact of grant-making and financial investing (Sprecher et al. 2016).

Although data availability has increased, the situation is not comparable to the US. More likely, the Swiss regulation on transparency is similar to Germany. Philanthropy is part of the private sphere, whereas in the US, it is part of the public sphere in terms of communication, promotion, and public awareness. For instance, in Switzerland most major donors stick to the rule "You give, but you do not talk about it" while in the US lists of major philanthropists are frequently published in high circulation magazines and philanthropists speaking about their experiences as means to encourage others to give have become increasingly popular (Shavchuk 2016). Development to more transparency can only be expected through international pressure as a consequence of further demands on visibility of financial transactions and the international fight against terrorism.

The analysis of the purposes and approaches brought forward many similarities with Germany. The distribution of the purposes relief, protection, and change as well as the distribution of the approaches grant-making, operative, and mixed are comparable. However, grant-making foundations are more relevant for change than for protection, compared to the data from Germany. This is supported by the results on the distribution of fields. The three main fields of focus in Switzerland are culture and recreation, social services, and education and research almost in equal parts. While culture and recreation are fields mostly pursued by operating and mixed foundations, social services and research and education are pursued significantly by grant-making foundations. As a result grant-making foundations are more closely linked to the purpose of change than operating and mixed which mostly pursue fields related to the traditional purposes of relief and protection. These more detailed findings are in line with previous studies on the Swiss foundations sector and underline the liberal self-concept of grant-making foundations in Switzerland. 
A widely neglected type of foundation in Switzerland is the international organizations, especially the so called "G-foundations" such as the Global Fund, GAIN or GAVI. Switzerland offers many advantages for this kind of organization. First, its humanitarian tradition as founding place of the Red Cross movement offers internationally operating organizations many institutional and fiscal advantages. Second, the competencies of the financial market allow for money transfers in all areas of the world. This is important for both, donors and beneficiaries. Third, Switzerland is accessible directly from all areas of the world with low travel restrictions to foreigners. Hence, in the current global political and economic situation, Switzerland develops into a hub of global philanthropy which might as well influence the national foundation sector and lead to further transfer of knowledge and concepts. In order to succeed in this development, Switzerland has to strike a balance between public expectations on transparency and international standards on the one hand, and the search for privacy and flexibility on the other hand.

\section{Acknowledgments}

We would like to thank Irene Reynolds and Thomas Starzynski for their support in data collection and data extraction.

\section{References}

Anheier, H. K., \& Daly, S. (Eds.) (2007). The politics of foundations. A comparative analysis. Florence: Routledge.

Arrivillaga, L.R., \& von Schnurbein, G. (2014). The Swiss Legal Framework on Foundations and Its Principles About Transparency. International Journal of Not-for-Profit Law, 16:1, 30-58.

Bambra, C. (2006). Decommodification and the worlds of welfare revisited. Journal of European Social Policy, 16:1, 73-80. 
Eckhardt, B., Jakob, D. \& von Schnurbein, G. (eds.) (2017). The Swiss Foundation Report 2016. Basel: CEPS.

Esping-Andersen, G. (1990). The three worlds of welfare capitalism. Princeton, N.J:

Princeton University Press.

Gerber J.D. \& Gerber, J. F. (2017). Decommodification as a foundation for ecological economics. Ecological Economics, 131, 551-556.

Hall, P. A. \& Soskice, D. W. (2001). Varieties of Capitalism. The institutional foundations of comparative advantage. Oxford: Oxford University Press.

Hammack, D.\& Anheier, H. K. (2013). A versatile Institution. Washington: Brookings.

Helmig, B., Gmür, M, Bärlocher, Ch., von Schnurbein, G., Degen, B., Nollert, M., Budowski, M., Sokolowski, W. \& Salamon L.M. (2011). The Swiss Civil Society Sector in a Comparative Perspective. Freiburg: VMI.

Leat, D. (2016). Philanthropic foundations, public good and public policy. London: Palgrave Macmillan.

Müller-Jentsch, D. (2014). Schweizer Stiftungswesen im Aufbruch. Zürich: Avenir Suisse.

Purtschert, R., von Schnurbein, G. \& Beccarelli, C.(2007). Switzerland. In H.K. Anheier \& S. Daly (Eds.) The Politics of Foundations. A Comparative Analysis, (pp. 307-323). Florence: Routledge.

Salamon, L. M., Anheier, H. K. \& Associates (1999). The emerging nonprofit sector revisited. An overview. Center for Civil Society Studies, Johns Hopkins University at <http,//ccss.jhu.edu/publications-findings $>$.

Shavchuk, K. (2016). Meet America's Top Givers Of 2015. Forbes, October 5, 2016 at < https:// www.forbes.com/sites/katiasavchuk/2016/10/05/meet-americastop-givers-of-2015/\#6f193d4528e4>

Scruggs, L. \& Allan, J.P. (2008). Social stratification and welfare regimes for the twenty-first Century. World Politics, 60, 642-664.

Sprecher, Th., Egger, Ph. \& von Schnurbein, G. (2016). Swiss Foundation Code 2015, English Edition. Foundation Governance, 13. Basel: Helbing Lichtenhahn. 
von Schnurbein, G. (2013). Der Nonprofit-Sektor in der Schweiz, In R. Simsa, M.

Meyer \& Ch. Badelt (Eds.) Handbuch der Nonprofit-Organisation, 5 (pp. 37-54). Auflage, Schäffer-Poeschel Verlag.

von Schnurbein, G. (2010). Foundations as Honest Brokers between Market, State, and Nonprofits. European Management Journal, 28:6, 413-420 
Figure 1. Development of the Swiss foundation sector 1896-2016

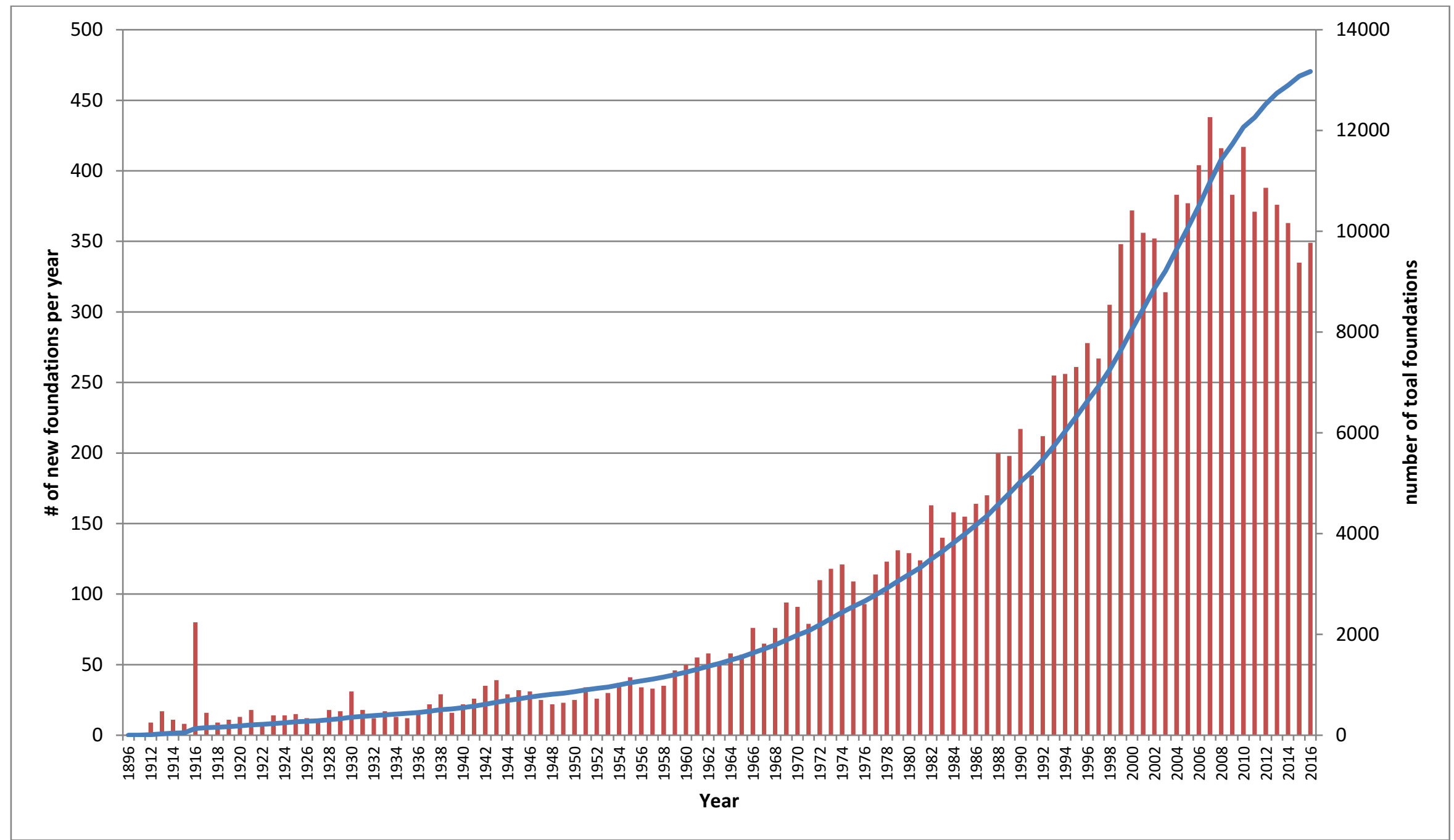

(Source: CEPS) 
Figure 2. The balance of approach, roles and purposes of Swiss foundations

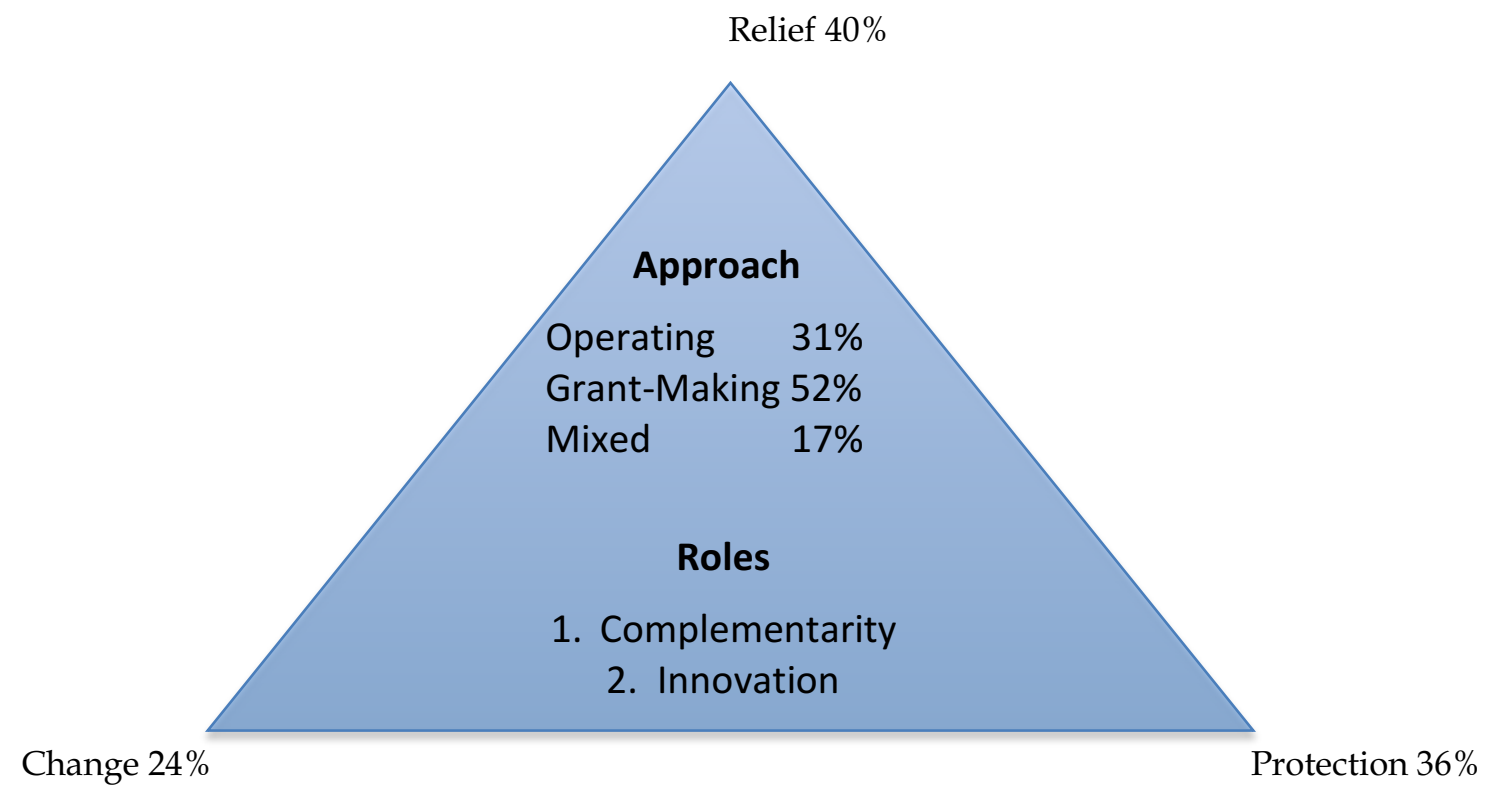


Table 1. Number of foundation and foundation density in the six cantons with the largest amount of foundations

\begin{tabular}{|c|c|c|}
\hline Canton & $\begin{array}{c}\text { Total } \\
\text { foundations }\end{array}$ & $\begin{array}{c}\text { Foundation } \\
\text { density (no. of } \\
\text { foundations/10000 } \\
\text { inhabitants) }\end{array}$ \\
\hline Zurich & 2262 & 15.4 \\
\hline Vaud & 1413 & 18.3 \\
\hline Berne & 1380 & 13.6 \\
\hline Geneva & 1174 & 24.2 \\
\hline Basel & 882 & 46.0 \\
\hline Tessin & 791 & 22.5 \\
\hline Total Switzerland & 13172 & 15.8 \\
\hline
\end{tabular}

(Source: CEPS) 
Table 2. Geographical focus of Swiss foundations

\begin{tabular}{lcc}
$\begin{array}{l}\text { Geographical } \\
\text { focus }\end{array}$ & $\begin{array}{c}\text { Number of } \\
\text { foundations }\end{array}$ & Percentage \\
\hline Local & 3304 & $30.8 \%$ \\
Cantonal & 1981 & $18.5 \%$ \\
National & 3013 & $28.1 \%$ \\
International & 2421 & $22.6 \%$ \\
\hline Total & 10719 & $100.0 \%$
\end{tabular}

(Source: CEPS) 
Table 3. Distribution of main fields of activity

\begin{tabular}{lccc} 
& $\begin{array}{c}\text { Proportion of } \\
\text { foundations } \\
\text { focused on } \\
\text { multiple fields }\end{array}$ & $\begin{array}{c}\text { Proportion of } \\
\text { foundations } \\
\text { focused on one }\end{array}$ & \\
Activity fields & $\mathbf{( \% )}$ & field & \\
\hline Culture and recreation & 1132 & $\mathbf{( \% )}$ & TOTAL \\
\hline Education and research & $(30)$ & 2646 & 3778 \\
Health & 1388 & $(70)$ & $(100)$ \\
& $(42)$ & 1929 & 3317 \\
Social services & 562 & $(58)$ & $(100)$ \\
& $(35)$ & 1053 & 1615 \\
Environment & 1564 & $(65)$ & $(100)$ \\
& $(44)$ & 1989 & 3553 \\
& 453 & $(56)$ & $(100)$ \\
& $(47)$ & 518 & 971 \\
\hline
\end{tabular}

(Source: CEPS) 
Table 4. Foundations based on size and development

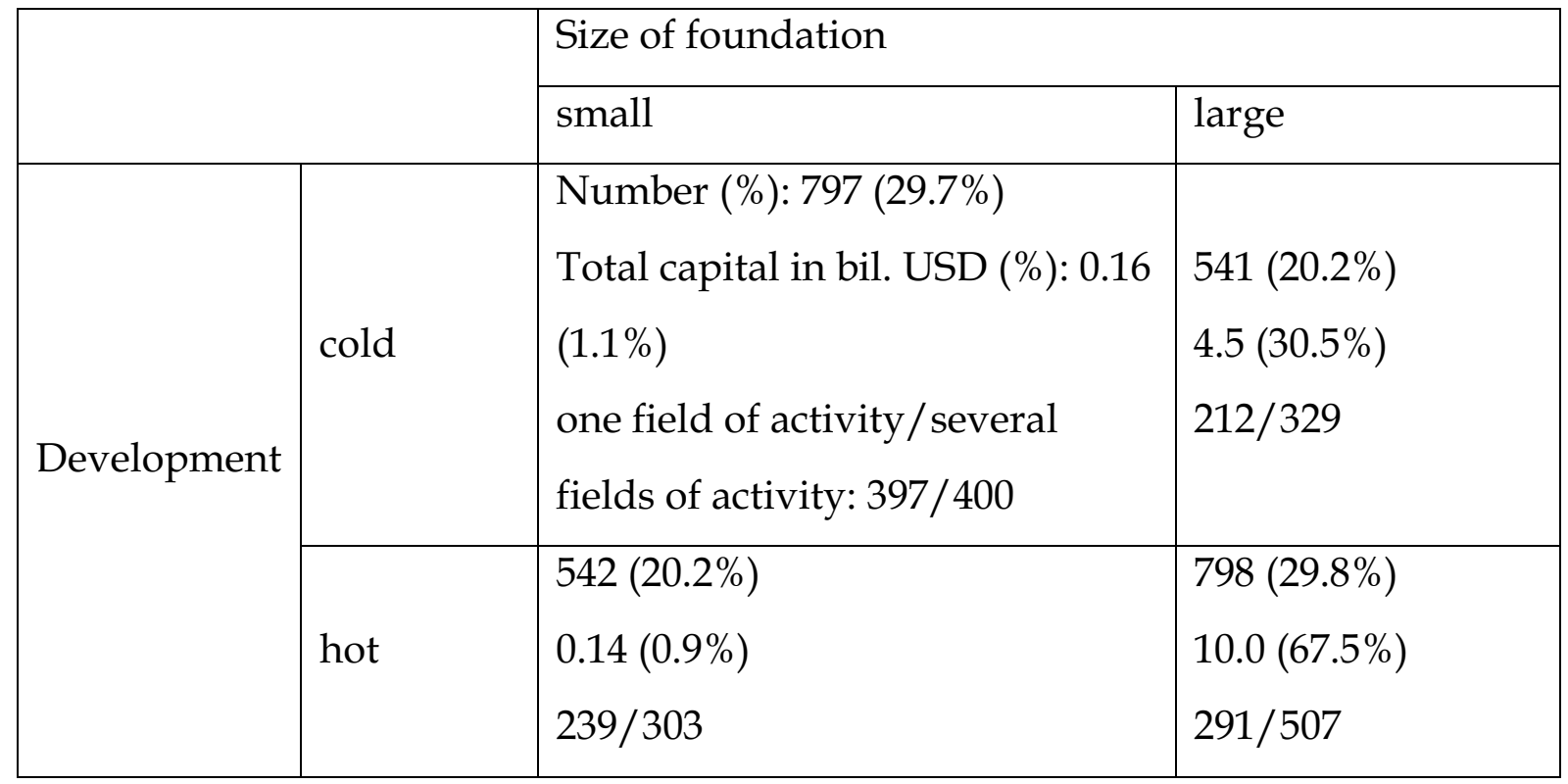

(Source: CEPS) 
Table 5. Relation between purpose and approach

\begin{tabular}{lcccc} 
& $\begin{array}{c}\text { Relief } \\
\mathbf{( \% )}\end{array}$ & $\begin{array}{c}\text { Change } \\
\mathbf{( \% )}\end{array}$ & $\begin{array}{c}\text { Protection } \\
\mathbf{( \% )}\end{array}$ & $\begin{array}{c}\text { Total } \\
\mathbf{( \% )}\end{array}$ \\
\hline Operating & 1238 & 436 & 1568 & 3242 \\
& $(38)$ & $(13)$ & $(48)$ & $(31)$ \\
Grant-making & 2389 & 1657 & 1432 & 5478 \\
& $(44)$ & $(30)$ & $(26)$ & $(52)$ \\
Mixed & 577 & 424 & 774 & 1775 \\
& $(33)$ & $(24)$ & $(44)$ & $(17)$ \\
\hline
\end{tabular}

(Source: CEPS) 
Table 6. Relation between fields and approach

\begin{tabular}{lccccc} 
& \multicolumn{3}{c}{ Education } & & \\
& Culture and & and & & Social & \\
& recreation & research & Health & services & Environment \\
& $(\mathbf{( \% )}$ & $\mathbf{( \% )}$ & $\mathbf{( \% )}$ & $\mathbf{( \% )}$ & $\mathbf{( \% )}$ \\
\hline Operating & 1406 & 447 & 635 & 615 & 170 \\
Grant-making & $(41)$ & $(15)$ & $(43)$ & $(19)$ & $(20)$ \\
& 1452 & 2041 & 594 & 2201 & 475 \\
Mixed & $(42)$ & $(69)$ & $(40)$ & $(69)$ & $(55)$ \\
& 596 & 473 & 265 & 369 & 220 \\
\hline Total & $(17)$ & $(16)$ & $(18)$ & $(12)$ & $(25)$ \\
\hline
\end{tabular}

(Source: CEPS) 